\title{
Formation of Ag Clusters by Electron Beam Irradiation of Ag-Zeolites
}

\author{
Yukichi Sasaki* and Toshiyuki Suzuki \\ Japan Fine Ceramics Center, Nagoya 456-8587, Japan
}

Zeolites possess excellent ion exchange capabilities, so that it is easy to synthesize Ag-zeolite $\left(\mathrm{Ag}_{x} \mathrm{Al}_{x} \mathrm{Si}_{1-x} \mathrm{O}_{2}\right)$ using an $\mathrm{AgNO}_{3}$ aqueous solution. When this Ag type zeolite is irradiated with a high energy electron beam of several hundred keV in a TEM, the chemical bonds in the zeolite crystal are broken and the crystal eventually becomes amorphous. (L. A. Bursill, E. A. Lodge and J. M. Thomas: Nature 286 (1980) 111113.) We have found that ordered clusters of Ag atoms are formed in the amorphous region during this process. It is anticipated that quantum effects will appear in this material. (Y. Nozue, T. Kodaira and T. Goto: Phys. Rev. Lett. 68 (1992) 3789.) [doi:10.2320/matertrans.MC200809]

(Received November 4, 2008; Accepted December 18, 2008; Published April 25, 2009)

Keywords: zeolite, silver cluster, electron beam irradiation, transmission electron microscopy

\section{Introduction}

To date, 130 kinds of zeolite have been synthesized with the framework structures of these crystals comprised of $\mathrm{Si}, \mathrm{Al}$ and $\mathrm{O}$ atoms. $\mathrm{Al}$ atoms have tetrahedral oxygen coordination, the same as $\mathrm{Si}$, in the zeolite framework, so that the $\mathrm{Al}$ atoms have a net charge of -1 . $\mathrm{Na}^{+}$ions are added to the zeolite crystal to retain electrical neutrality. Therefore, the number of $\mathrm{Na}^{+}$ions must be the same as the number of $\mathrm{Al}$ atoms, so that the chemical formula of Na-type zeolites can be written $\mathrm{Na}_{x} \mathrm{Al}_{x} \mathrm{Si}_{1-x} \mathrm{O}_{2}$. Ag type zeolites $\left(\mathrm{Ag}_{x} \mathrm{Al}_{x} \mathrm{Si}_{1-x} \mathrm{O}_{2}\right)$ are readily synthesized by reaction between Na-type zeolites and silver nitrate aqueous solution. ${ }^{1)}$

The crystal structure of this Ag type zeolite is gradually disrupted by a $200 \mathrm{keV}$ electron beam in a transmission electron microscope (TEM), finally becoming amorphous. ${ }^{2)}$ During this process, lattice fringes from the crystal structure disappeared and new lattice fringes appeared.

\section{Experimental Methods}

Ag-type LTA and FAU zeolites were synthesized by reaction between ordinary $\mathrm{Na}$ type zeolites (LTA zeolite: $\mathrm{Si} / \mathrm{Al}=1$, channel size $\langle 100\rangle 0.41 \mathrm{~nm}$, FAU zeolite: $\mathrm{Si} /$ $\mathrm{Al}=2.8$, channel size $\langle 111\rangle 0.74 \mathrm{~nm}$ ) and silver nitrate aqueous solution. Powder of these Ag-type zeolites were dispersed in ethanol. Next, drops of the slurry were put on a $\mathrm{Cu}$ microgrid to support the fragments of zeolites. TEM observations were performed on a JEOL EM-2010 operating at $200 \mathrm{kV}$ under low-dose observation conditions. A slowscan charge-coupled-device (SSC) camera (model 679, Gatan) was attached to the TEM, and recorded of images were monitored on the computer in real time.

\section{Results and Discussions}

Figure 1 shows lattice fringes in an Ag type LTA zeolite irradiated with an electron beam of $200 \mathrm{keV}$. The lattice pacing and arrangements of the dark dots correspond to the particular distribution of $\alpha$-sodalite cages in the LTA zeolite. The chemical composition of these dots was shown to be $\mathrm{Ag}$ metal by energy dispersive X-ray spectroscopy (EDS)

*Corresponding author, E-mail: sasaki@jfcc.or.jp analysis. We conclude that the black dots correspond to Ag clusters with sizes of approximately $1 \mathrm{~nm}$, very similar to the size of an $\alpha$-sodalite cage.

A TEM micrograph of another Ag type zeolite, FAU, irradiated with an electron beam is shown in Fig. 2. Black spots similar to those in the LTA zeolite also appeared in the FAU zeolite. The arrangement of these black spots matches the distribution of the super cages in the FAU zeolite. As evidenced by these results, the distribution of the Ag clusters corresponds to the pore arrangements in the zeolite crystals. In other words Ag clusters have formed in the pores of the zeolite crystals, and the clusters are distributed three-dimensionally as illustrated in the left-hand inset of Fig. 1 in the case of LTA. We can conclude therefore that Ag clusters were produced by irradiation of the Ag type zeolites.

Figure 3 shows the change in microstructure that occurs during irradiation of the FAU zeolite in a TEM. The crystal lattice is clearly visible during the early stages of electron beam irradiation, but the lattice fringes corresponding to the framework structure of the zeolite disappear soon afterwards (Fig. 3(a)). A black pattern of spots appears as electron beam irradiation is continued (Fig. 3(b)). This lattice pattern reveals the spatial distribution of metallic Ag. Finally, Ag atoms coalesce on the zeolite powder surface to form nanoparticles (Fig. 3(e)). Figure 4 shows a cross sectional TEM image of an Ag particle precipitated on a zeolite surface. The Ag clusters are observed to have the same lattice structure within the zeolite particle, and the distance between each lattice fringe is approximately $1 \mathrm{~nm}$ in both cases. This lattice structure remains even when the Ag particle has coalesced on the zeolite surface. This TEM micrograph is therefore evidence that Ag cluster crystals form inside of the zeolite particle and then diffuse to the surface.

A possible mechanism for formation of the $\mathrm{Ag}$ cluster crystals is illustrated in Fig. 5. In the defect free zeolite, Al has tetrahedral oxygen coordination, the same as $\mathrm{Si}$, even though it has a net charge of -1 relative to the silica matrix. $\mathrm{Ag}^{+}$ions therefore associate with $\mathrm{Al}$ ions in order to maintain charge neutrality. When chemical bonds in the zeolite are broken by electron beam irradiation, the zeolite crystals change to amorphous materials. ${ }^{3,4)}$ It is speculated that $\mathrm{Al}$ switches to six-fold oxygen coordination to stabilize the structure in the amorphous materials. The Ag atoms no 


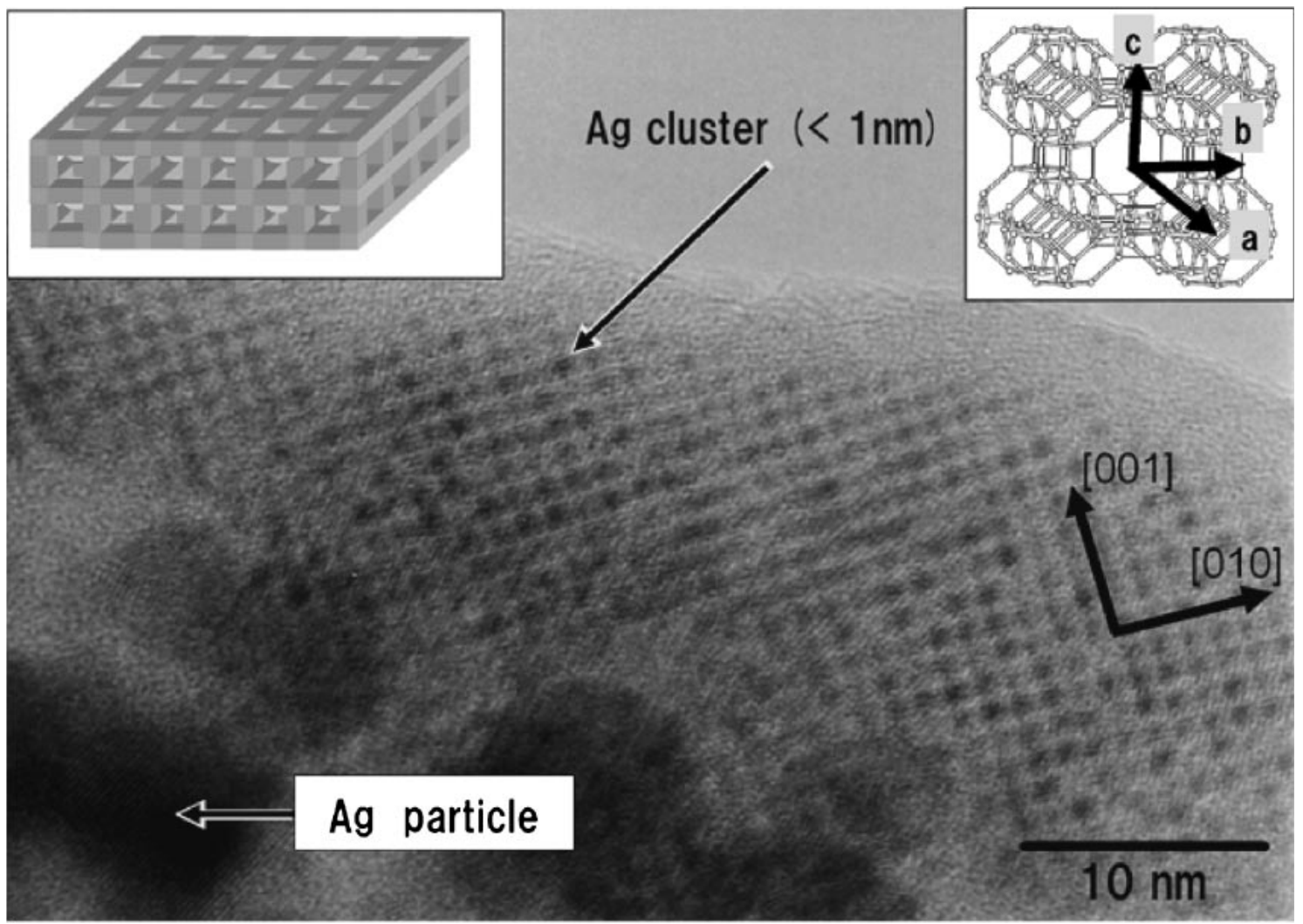

Fig. 1 Lattice image formed in an Ag type LTA zeolite irradiated with $200 \mathrm{keV}$ electron beam. Each black dot corresponds to an Ag cluster, and the size of each cluster is approximately $1 \mathrm{~nm}$. The framework structure of LTA zeolite is illustrated in the right insert.

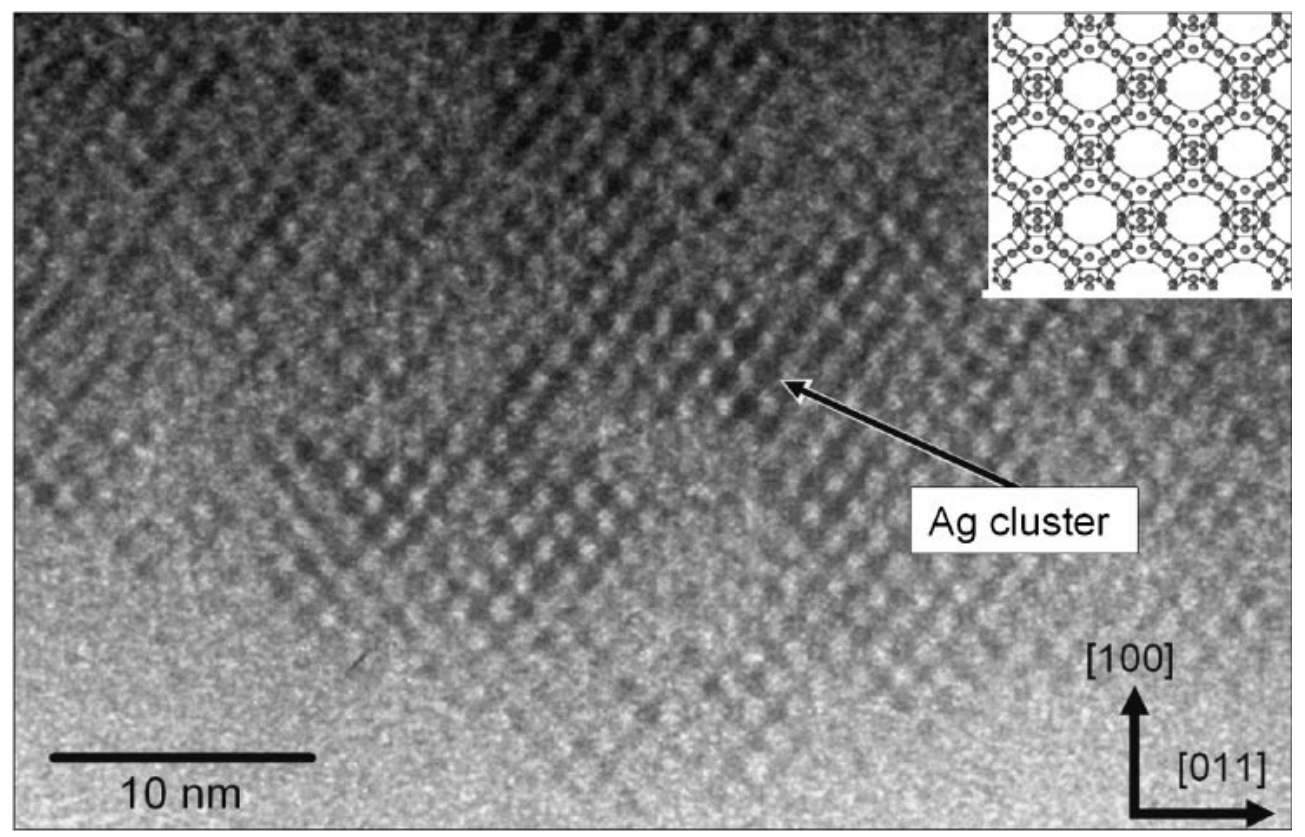

Fig. 2 Lattice image formed in an Ag type FAU zeolite irradiated with $200 \mathrm{keV}$ electron beam.

longer experience any electrostatic constraints, so some $\mathrm{Ag}$ atoms agglomerate to form sub-nanometer-sized clusters by diffusing through the amorphous silica. However, the pore channel structure remains, even after the crystal lattice of the zeolite framework has been destroyed by the electron beam. The Ag clusters selectively form in the pores, and are aligned in the same direction as the pores. Finally, the Ag diffuses to the surfaces of the zeolite particles, so that the clusters become more stable by coalescing as nano-size particles. The same phenomenon is expected to occur in zeolites exchanged with metal ions having similar properties to $\mathrm{Ag}^{+}$. Ag clusters should be formed in the pores of amorphous $\mathrm{SiO}_{2}$, which has a similar pore channel structure to the crystalline zeolites. We estimate that clusters formed 

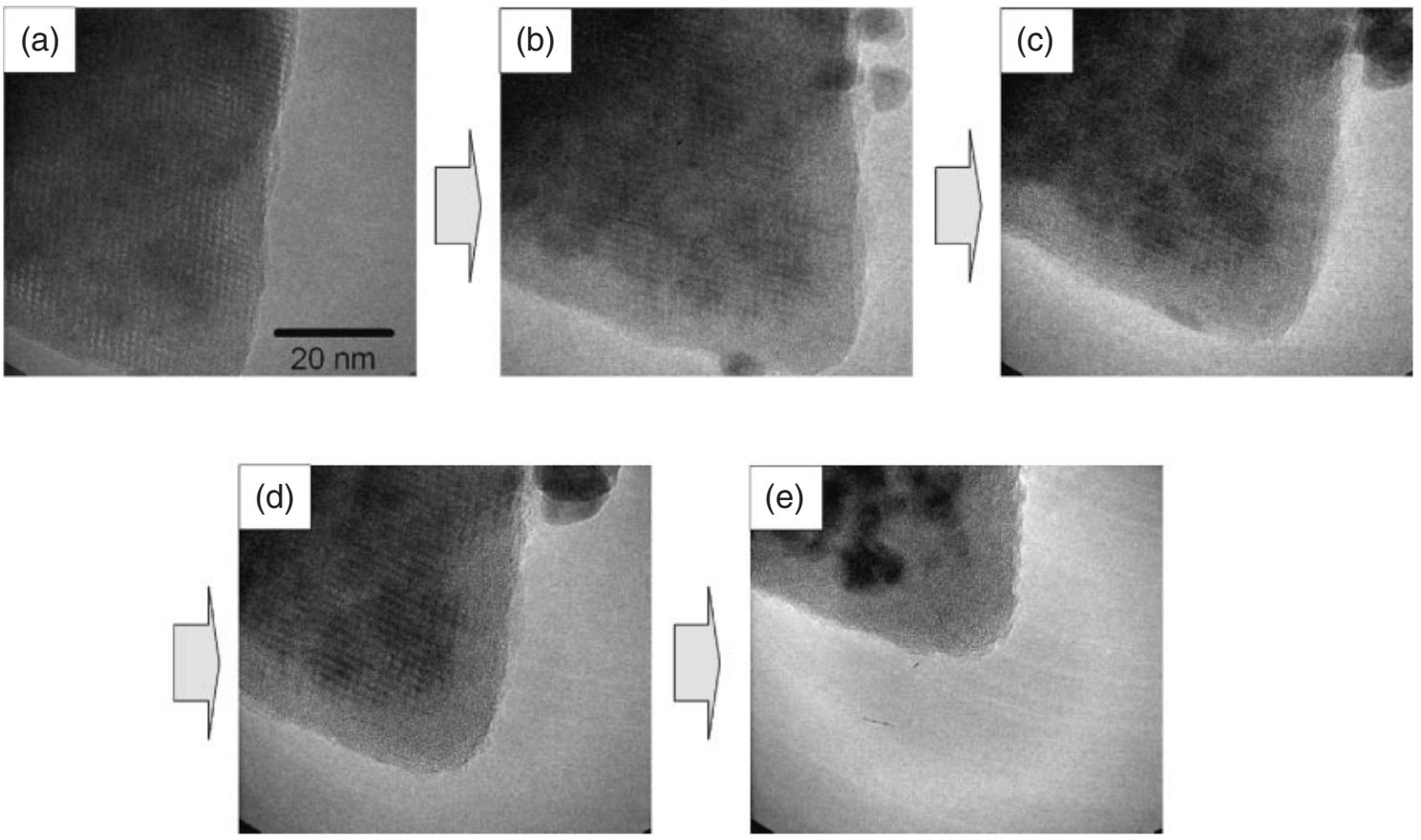

Fig. 3 Change in microstructure by electron beam irradiation of the FAU zeolite in a TEM.

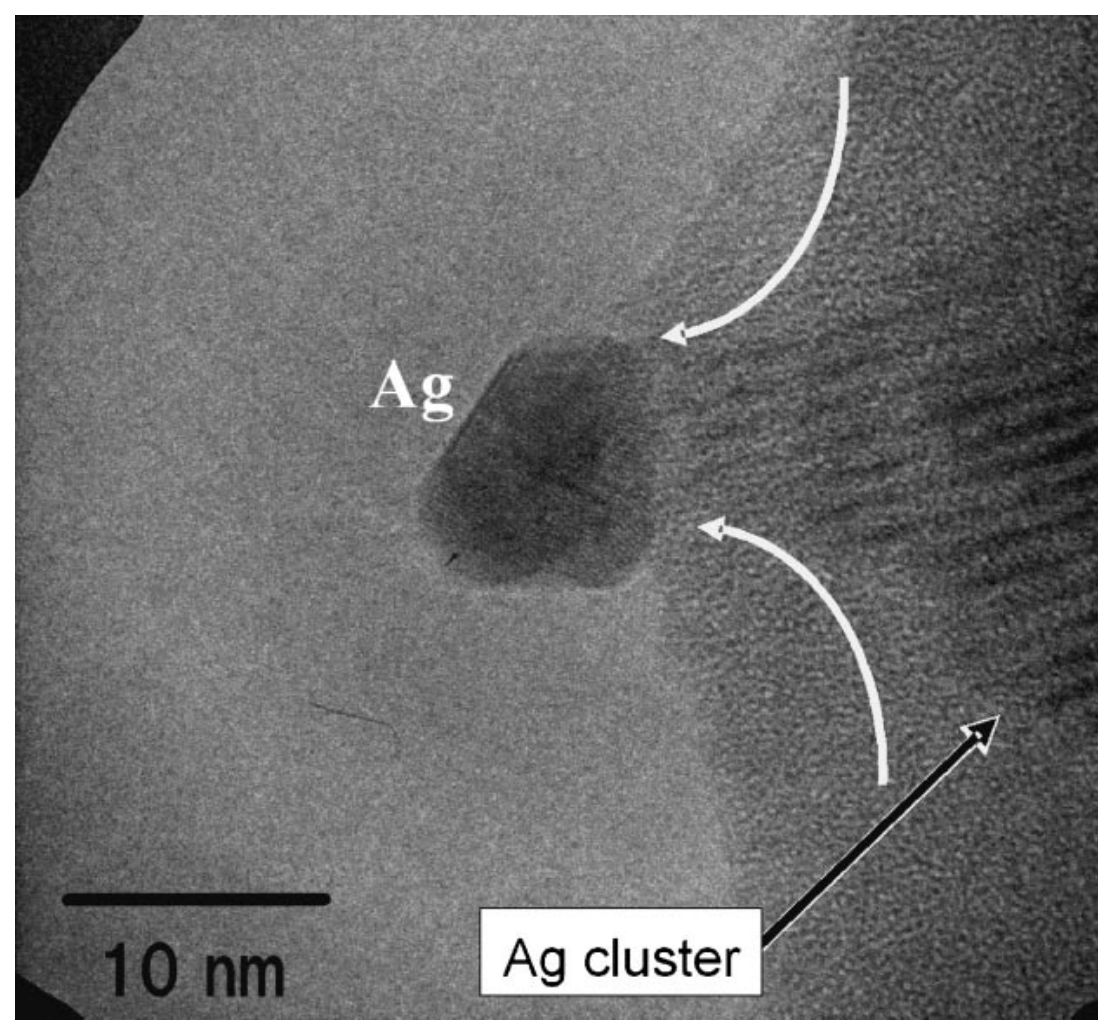

Fig. 4 Ag particle precipitated on a zeolite surface. This figure suggests that Ag cluster crystals form inside of the zeolite particle and then diffuse to the surface.

in Ag-type LTA zeolite consist of $96 \mathrm{Ag}$ atoms, and in $\mathrm{Ag}$ type FAU zeolite of 60 to $65 \mathrm{Ag}$ atoms.

\section{Concluding Remarks}

We have found that cluster crystals are formed by electron beam irradiation of $\mathrm{Ag}$ type zeolites. It seems that producing the uniform clusters crystal in the zeolite crystal using high energy electron beam irradiation is not straightforward, because the electron beam irradiation breaks chemical bonds of the zeolite framework and simultaneously activates rapid diffusion of $\mathrm{Ag}$ clusters in the amorphous $\mathrm{SiO}_{2}$, so that the process is difficult to control. However, if we can control diffusion of the Ag clusters 

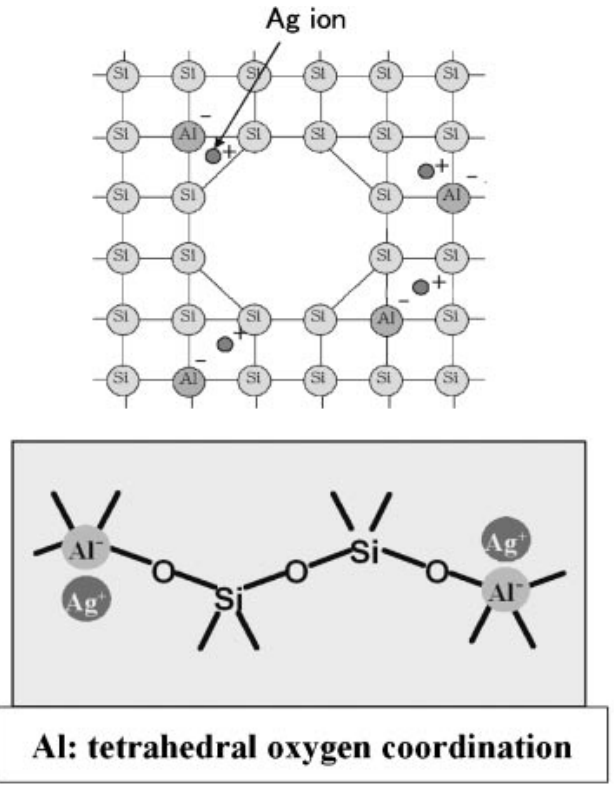

Before irradiation

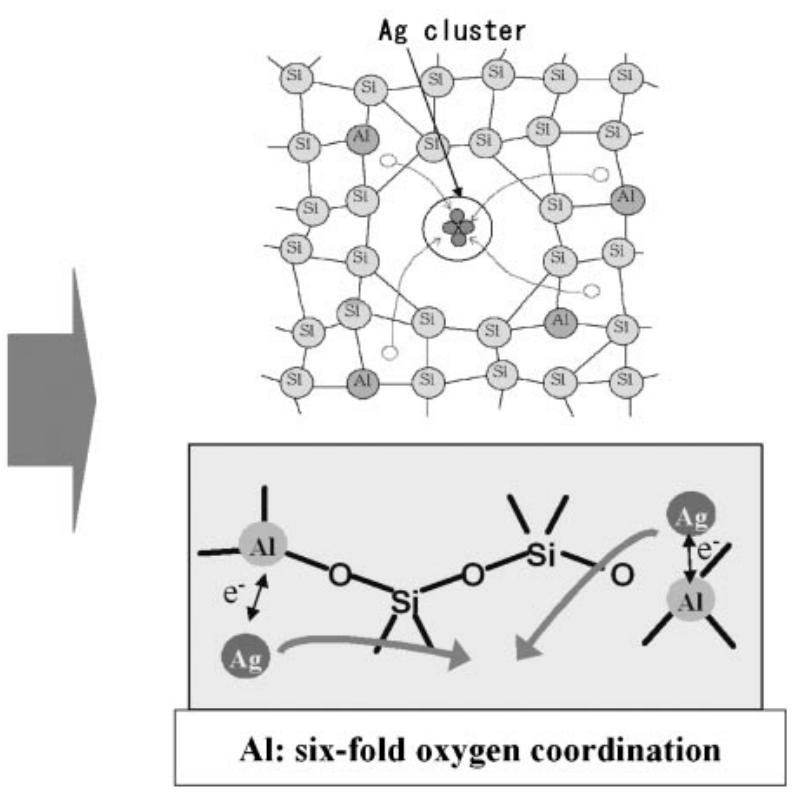

After irradiation

Fig. 5 Formation mechanism of Ag cluster crystals. They are aligned in the same direction as the pores.

while breaking the chemical bonds of the zeolite framework by heating and/or electromagnetic irradiation under steam, it should be possible to produce cluster crystals of uniform size. Recently, synthesis methods have been developed to obtain single crystals of LTA and FAU zeolites several hundred microns in size. ${ }^{5)}$ In addition, oriented films centimeters in length have also been prepared. $\left.{ }^{6}\right)$ We expect that cluster crystal device could be developed by this method using zeolites exchanged with several kinds of metal ions.

\section{Acknowledgements}

This work was partially supported by a Grant-in-Aid for Scientific Research on Priority Areas "Nano Materials
Science for Atomic Scale Modification 474" from the Ministry of Education, Culture, Sports, Science and Technology (MEXT) of Japan.

\section{REFERENCES}

1) N. E. Bogdanchikova, A. V. Toktarev, V. N. Kolomiichuk, V. I. Zalokovskii, M. N. Dulin and G. B. Shevnina: React. Kinet. Catal. Lett. 49 (1993) 87.

2) L. A. Bursill, E. A. Lodge and J. M. Thomas: Nature 286 (1980) 111.

3) H. Ikeda, Y. Murayama, Y. Ohoka, K. Morinaga and T. Yanagase: J. Japan Inst. Metals 47 (1983) 1063-1067.

4) T. Hanada and N. Soga: J. Am. Ceram. Soc. 65 (1982) C-84.

5) S. Yamamoto, S. Sugiyama, O. Matsuoka, K. Kohmura, T. Honda, Y. Banno and H. Nozoye: J. Phys. Chem. 100 (1996) 18474.

6) J. Hedlund, B. Schoeman and J. Sterte: Chem. Commun. (1997) 1993. 